\title{
THE RATE OF GASTRIC SECRETION IN MAN
}

\author{
BY ARTHUR L. BLOOMFIELD AND CHESTER S. KEEFER
}

(From the Department of Medicine, Stanford University School of Medicine, San Francisco, and the Department of Medicine, Johns Hopkins University, Baltimore)

(Received for publication May 16, 1927)

The lack of methods for estimating accurately the volume of gastric secretion in man has made it difficult to determine just how much gastric juice is produced by the stomach in response to various stimuli. Clinicians have generally assumed, however, that after the introduction of food or other stimuli secretion gradually increases, and reaches a maximum only after an interval which may be as long as an hour or more. This view is evidently based on the titration of acid values of specimens removed from the stomach during the course of a "fractional analysis."

The literature on the types of "acid curve" obtained by the fractional Rehfuss meal is reviewed by Crohn and Reiss (1). It may be recalled that isosecretory, hypersecretory and hyposecretory types are distinguished on the basis of the degree of acidity and the time after the introduction of the test meal when the high point is reached. Still other types of curve have been related to various gastric disorders.

The ordinary fractional method of gastric analysis yields, however, only the vaguest information about the volume of gastric juice, nor do the usual rising curves of acidity have any constant relation to the acidity of the actual gastric juice inasmuch as the titration values are modified by two unknown factors, namely, the rate at which the test meal is diluted by gastric secretion and the rate at which the stomach empties. In brief, the conventional methods of gastric analysis do not tell whether gastric secretion gradually increases after stimulation, or whether stimulation is promptly followed by a maximum response both as regards volume of secretion and degree of acidity.

By means of a method which we recently described (2), it is possible to estimate the acidity of the pure gastric juice as well as the volume of gastric juice secreted in successive ten minute periods after stimu- 
lation by $50 \mathrm{cc}$. of 7 per cent alcohol. The results indicate that under the conditions of these observations gastric secretion usually begins promptly after stimulation and is almost immediately at a maximum, both as regards amount and acidity, and that the slow evolution of gastric secretion, which is generally believed to be the rule, rarely takes place.

\section{MATERIAL AND METHODS}

Observations were made in a consecutive series of people. Some were "normal;" some were ill with digestive or other disorders.

The method for testing gastric activity after introduction of $50 \mathrm{cc}$. of 7 per cent alcohol into the stomach was used exactly as previously described (2). The amounts of gastric secretion produced during successive ten-minute periods after stimulation were determined, as well as the titratable acidity (in terms of cubic centimeters of $\mathrm{N} / 10$ $\mathrm{NaOH}$, with phenolphthalein as indicator) of the pure juice.

The method is, briefly, as follows:

The subject should take no food during the twelve hours preceding the test. If possible, he should be under "basal" conditions; i.e., resting quietly in bed.

A duodenal tube is passed to a distance which will allow the tip to reach the most dependent part of the stomach. The fasting juice is withdrawn at five-minute intervals for fifteen or twenty minutes. Then, without attracting the patient's attention, $50 \mathrm{cc}$. of 7 per cent alcohol to which $0.5 \mathrm{cc}$. of 1 per cent alcoholic phenolphthalein has been added is injected by means of a large glass $(100 \mathrm{cc}$.) syringe through the tube into the stomach. The entire gastric contents are then immediately withdrawn, measured in the syringe and reinjected, save for $10 \mathrm{cc}$. which are kept for analysis. The patient is kept in a semirecumbent position, but during the aspiration is turned on both sides in order to make complete emptying of the stomach more certain. Ten minutes after the first aspiration, the stomach is again completely emptied, the contents are measured and returned except for the $10 \mathrm{cc}$. sample for analysis. This procedure is repeated at ten-minute intervals for one hour or until the stomach is empty (contents less than $10 \mathrm{cc}$.). It is very important that saliva is not swallowed during the test.

The samples are usually clear and limpid and are highly satisfactory for study.

The volume of gastric juice secreted in any ten-minute period may be calculated as follows:

As pointed out above, phenolphthalein has been added to the alcohol test meal. The various specimens aspirated at ten-minute intervals may be made alkaline, thus bringing out the red color of the dye, the concentration of which can then be readily determined by reading against a standard in a colorimeter. In this way 
the percentage dilution of the gastric contents at various intervals is calculated. Knowing this, and knowing the total volume of stomach contents at the beginning and at the end of each ten-minute period, the maximum and minimum possible volumes of secretion which would satisfy these fgures can be calculated by the following formula: $\left[\left(\frac{x}{y} \times A\right)\right]-A=$ maximum possible amount of juice secreted in ten-minute period, and B $-\left[\left(\frac{y}{x} \times B\right)\right]=$ minimum possible amount, in which $A$ equals the number of cubic centimeters of fluid in the stomach at the beginning of the period; $B$, the number of cubic centimeters at the end of the period; $x$, the concentration (percentage reading) of phenolphthalein at the beginning of the period, and $y$, the concentration at the end.

The actual amount of secretion evidently lies between the calculated maximum and minimum possibilities. These usually agree quite closely, so that an average can be taken which must be very near the true figure. In certain cases, however, especially when the stomach empties very quickly, the maximum and minimum values are so far apart that conclusions cannot be drawn as to actual volume of secretion. If the test is repeated on another occasion, satisfactory figures may be obtained.

The acidity of the pure juice present in the stomach at the time of each aspiration can be determined by the usual method of titration with a correction for dilution by the test meal on the basis of the percentage of dye present at the time. A more detailed statement of the technique may be found in the previous paper.

\section{RESULTS}

\section{The rate of gastric secretion after stimulation}

In table 1 and chart 1 are shown the volumes of gastric secretion during successive ten-minute periods after introduction of the alcohol meal. One sees that on the whole the volumes tend to decrease rather than to increase as time elapses after stimulation. Case 76 was an exception in so far as after forty minutes there was a marked increase in secretion. This patient had a duodenal ulcer. In a composite chart (no. 2) are shown the sums of the volumes of secretion for four ten-minute periods in all the cases in which complete observations over this length of time were available. This shows even more clearly the initial high value which tends to fall and not to rise.

\section{The curve of acidity after stimulation}

Table 2 and chart 3 show the corrected titratable acidity of the pure gastric juice before stimulation and at ten-minute intervals after 
introduction of the alcohol meal. In nearly every instance the juice attains its maximum or nearly its maximum acidity within ten minutes after stimulation regardless of the fasting value. If allowance is made for the error inherent in the methods one may conclude that stimulation is followed almost immediately by a secretion of maximum acidity; the actual level attained may be high or low. In occasional cases (nos. 92, 198) there was a continued steady rise, but this was never

TABLE 1

Volumes of gastric secretion for ten-minute periods after alcohol meal

\begin{tabular}{|c|c|c|c|c|c|c|c|}
\hline $\begin{array}{c}\text { Case } \\
\text { number }\end{array}$ & Diagnosis & Period 1 & Period 2 & Period 3 & Period 4 & Period 5 & Period 6 \\
\hline & & 50 & 52. & $c c$. & $c c$. & $c c$ & $c c$. \\
\hline $\begin{array}{r}156 \\
92\end{array}$ & $\begin{array}{l}\text { Gastric ulcer } \\
\text { Normal }\end{array}$ & $\begin{array}{l}59 \\
47\end{array}$ & $\begin{array}{l}52 \\
52\end{array}$ & 49 & 33 & 22 & \\
\hline 76 & Duodenal ulcer & 43 & 36 & 40 & 31 & 67 & 71 \\
\hline 198 & Normal & 27 & 40 & 15 & 29 & 17 & \\
\hline 178 & Chronic myocarditis & 27.5 & 24 & 18 & 12 & 11.5 & 8 \\
\hline 180 & Congenital syphilis & 27 & 17.5 & 12 & 6.5 & 3 & \\
\hline 146 & Psychoneurosis & 25.5 & 30.5 & 31 & 26 & 38 & \\
\hline 236 & Normal & 25 & 21 & 16 & & & \\
\hline 80 & Normal & 24 & 15 & 13 & 13 & 12 & 11 \\
\hline 54 & Bradycardia & 24.5 & 20 & 11 & 9.5 & 7 & \\
\hline 84 & Normal & 22 & 10 & 10 & 18.5 & 16.5 & 6.5 \\
\hline 196 & Normal & 21 & 16 & 20 & 15 & 7 & \\
\hline 122 & Normal & 20 & 17.5 & 14.5 & 7.5 & & \\
\hline 86 & Normal & 19 & 14.5 & 19.5 & 15 & 8.5 & \\
\hline 106 & Arteriosclerosis & 14 & 11.5 & 15.5 & 8 & 5 & 5 \\
\hline 94 & Arteriosclerosis & 10 & 12 & 13 & 6 & 5.5 & \\
\hline 214 & Normal & 14.5 & 24.5 & 11.5 & 18.5 & 8.5 & \\
\hline 174 & Chronic peritonitis & 12.5 & 10 & 10.4 & 7.8 & & \\
\hline 304 & Gastric ulcer & 23 & 53 & 30 & 18 & & \\
\hline 222 & Psychoneurosis & 23 & 25 & & & & \\
\hline
\end{tabular}

extreme in proportion to the initial rise immediately after stimulation. In a few other cases, on the contrary, the acidity seemed to fall from the start (nos. 106, 146). A composite chart (no. 4) confirms the essential features of the individual curves.

It appears, therefore, that the "alcohol meal" is followed not by a gradual evolution of gastric secretion but by a prompt and often maximal response, and it is important to reconcile these findings with 
those of the ordinary fractional meal, which usually shows a progressive rise in acidity. Several sources of error in interpretation are to

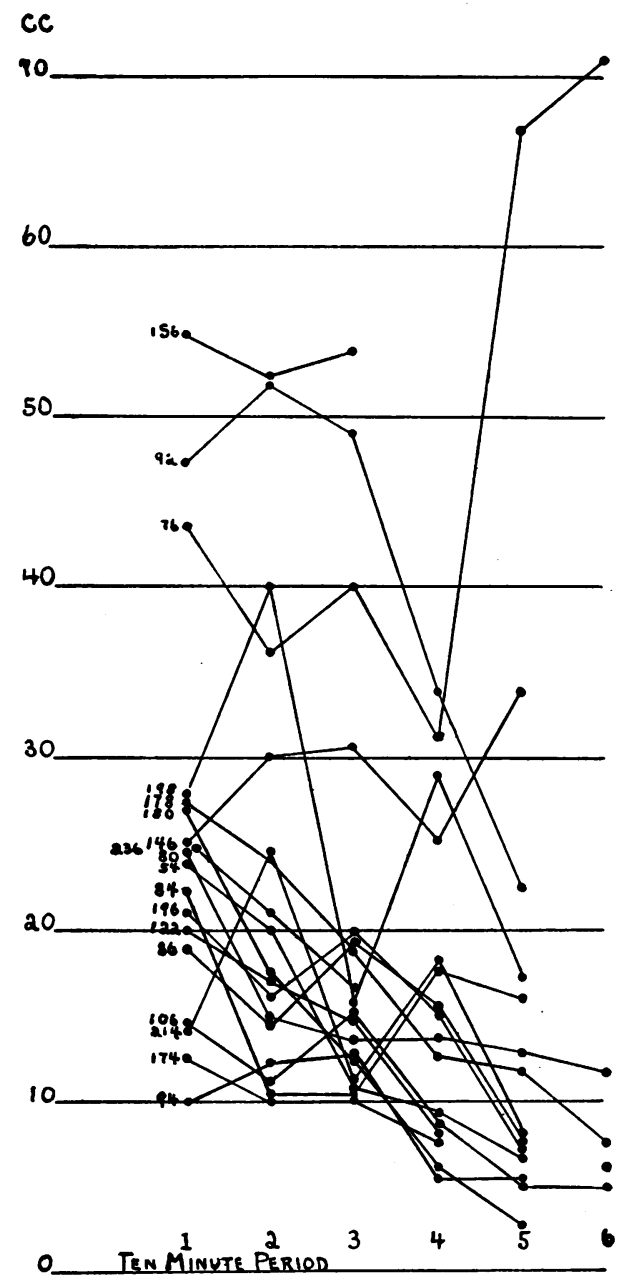

Chart 1. Volume of Secretion for Ten-Minute Pertods after Aicoholic MEAL

be considered. In the first place, as emphasized by Gorham (3), the acid actually secreted by the stomach is diluted by the fluid of the test meal. Clearly the acid values of specimens withdrawn at various

THE JOURNAL OF CLINTCAL nTVHETIGATION, VOL. IV, MO. 1 
intervals will depend not only on the amount of secretion but on the speed with which the test meal leaves the stomach. If the emptying is rapid a high acid value will be reached more quickly than if the diluent is retained in the stomach in large quantity. Furthermore, the buffer action of saliva and of the test meal mask the presence of acid until an excess has been secreted. In order to bring out the point more concretely the following experiments were done:

Experiment 1. The usual (Ewald) test meal of two slices of bread and $500 \mathrm{cc}$. of water was prepared, but instead of swallowing the meal, the patient expecto-

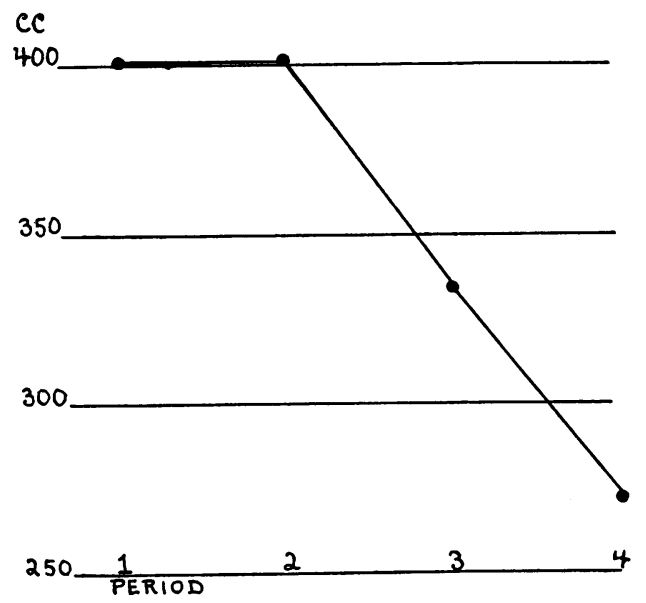

Chart 2. Sum of Secretory Volumes Shown in Chart 1

rated the mixture of bread and saliva into a large beaker in which it was thoroughly stirred up with the $500 \mathrm{cc}$. of water. The beaker roughly simulated the stomach immediately after in estion of the test meal. In order to simulate further a constant secretion of acid into a stomach which is emptying very slowly $20 \mathrm{cc}$. portions of $\mathrm{N} / 10 \mathrm{HCl}$ were added at intervals without removing any of the mixture except $10 \mathrm{cc}$. samples for titration after each addition of acid.

The results are shown in Chart 5, curve A. It may be noted that in spite of the uniform addition of acid no free $\mathrm{HCl}$ (di-methyl) was demonstrated until approximately $100 \mathrm{cc}$. of $\mathrm{N} / 10 \mathrm{HCl}$ had been introduced. Thereafter there was a steady increase. 
Experiment 2. In this experiment conditions were identical except that moderately rapid emptying of the stomach was simulated by removing $100 \mathrm{cc}$. of the test meal mixture before each addition of $20 \mathrm{cc}$. of acid. Chart 5, curve B, shows that in this case a "free $\mathrm{HCl}$ " value of 37 was reached at a point where in the previous experiment free $\mathrm{HCl}$ was just beginning to appear.

TABLE 2

Titratable acidity at ten-minute intervals after alcohol test meal

\begin{tabular}{|c|c|c|c|c|c|c|c|c|c|c|}
\hline $\begin{array}{l}\text { Case } \\
\text { num- } \\
\text { ber }\end{array}$ & Diagnosis & $\begin{array}{c}\text { Fast- } \\
\text { ing }\end{array}$ & $\begin{array}{c}10 \\
\text { min- } \\
\text { utes }\end{array}$ & $\underset{\text { min- }}{20}$ & $\begin{array}{c}30 \\
\text { min- } \\
\text { utes }\end{array}$ & $\underset{\text { min- }}{40}$ & $\begin{array}{c}50 \\
\text { min- } \\
\text { utes }\end{array}$ & $\underset{\text { utes }}{60}$ & $\begin{array}{c}70 \\
\text { min- } \\
\text { utes }\end{array}$ & $\begin{array}{c}80 \\
\text { min- } \\
\text { utes }\end{array}$ \\
\hline 156 & Gastric ulcer & 94 & 93 & 95 & 95 & & & & & \\
\hline 76 & Duodenal ulcer & 86 & 112 & 108 & 101 & 104 & 108 & 104 & & \\
\hline 34 & Duodenal ulcer & 75 & 100 & 103 & 102 & & & & & \\
\hline 92 & Normal & 80 & 87 & 92 & 101 & 104 & 104 & 106 & & \\
\hline 214 & Normal & 78 & 70 & 68 & 69 & 63 & 54 & & & \\
\hline 208 & Haematuria & 50 & 84 & 90 & 90 & 88 & 84 & & & \\
\hline 304 & Gastric ulcer & 42 & 102 & 110 & 118 & 113 & 114 & & & \\
\hline 192 & Chronic myocarditis & 36 & 81 & 85 & 96 & 93 & 94 & & & \\
\hline 178 & Chronic myocarditis & 60 & 96 & 92 & 98 & 92 & 87 & 83 & 54 & \\
\hline 180 & Congenital syphilis & 34 & 56 & 62 & 60 & 60 & & & & \\
\hline 122 & Normal & 30 & 55 & 59 & 51 & 56 & 55 & & & \\
\hline 146 & Psychoneurosis & 24 & 62 & 57 & 55 & 45 & & & & \\
\hline 80 & Normal & 20 & 32 & 37 & 35 & 40 & 43 & 42 & & \\
\hline 174 & Abdominal adhesions & 20 & 54 & 62 & 66 & 66 & 63 & & & \\
\hline 198 & Normal & 16 & 48 & 51 & 56 & 68 & 64 & & & \\
\hline 106 & Ateriosclerosis & 14 & 50 & 41 & 41 & 35 & 21 & 20 & & \\
\hline 94 & Arteriosclerosis & 0 & 34 & 38 & 30 & 30 & 34 & & & \\
\hline 182 & Pleurisy & 0 & 20 & 15 & 20 & 20 & 15 & & & \\
\hline 236 & Normal & 0 & 23 & 20 & 24 & & & & & \\
\hline 32 & Gall stones & 0 & 30 & 21 & 14 & 14 & 13 & & & \\
\hline 222 & Normal & 0 & 0 & 9 & 14 & & & & & \\
\hline 188 & Gonorrheal arthritis & 10 & 40 & 54 & 53 & 56 & & & & \\
\hline
\end{tabular}

These experiments were carried out with the reagents of the routine clinical laboratory and without attempting greater accuracy than one observes in the usual examination of test-meal specimens.

Similar experiments with tap water and with distilled water alone yielded analogous results except that owing to absence of the buffer effect of the test meal and saliva "free $\mathrm{HCl}$ " appeared sooner.

It is clear, then, that the so-called curves of acid secretion plotted from specimens removed at intervals after a test meal depend not on 


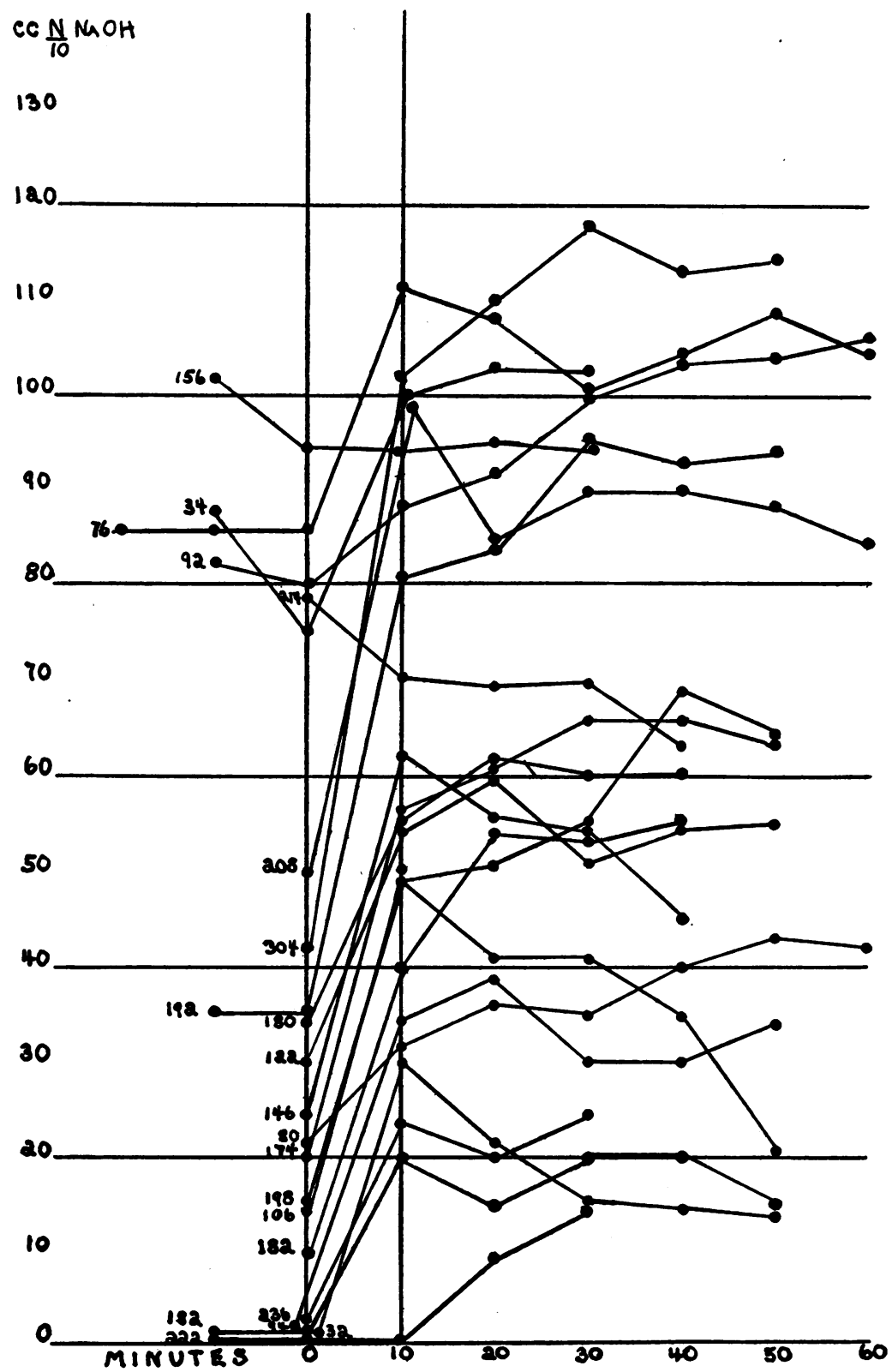

Chart 3. Titratable Acmity of Gastric Juice at Ten-Minute Intervals AFTER AICOHOL MEAL 

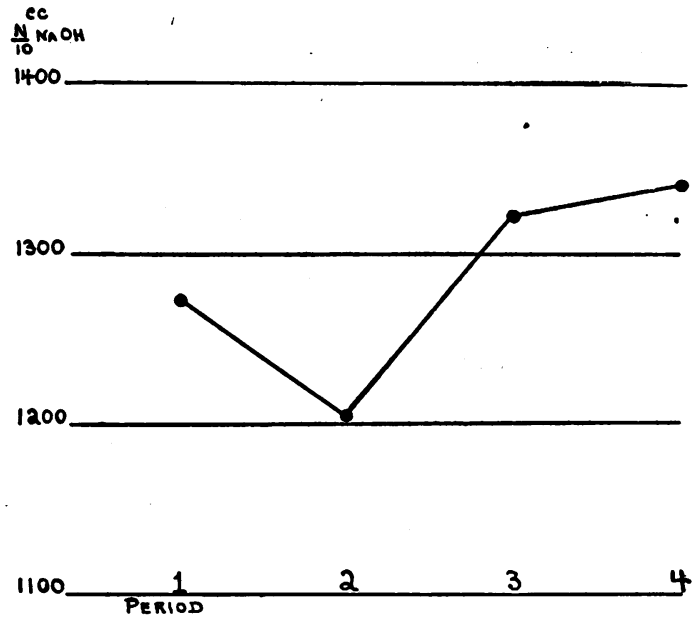

Chart 4. Composite Chart of Titratable Acmity in Cases Shown in Chart 3

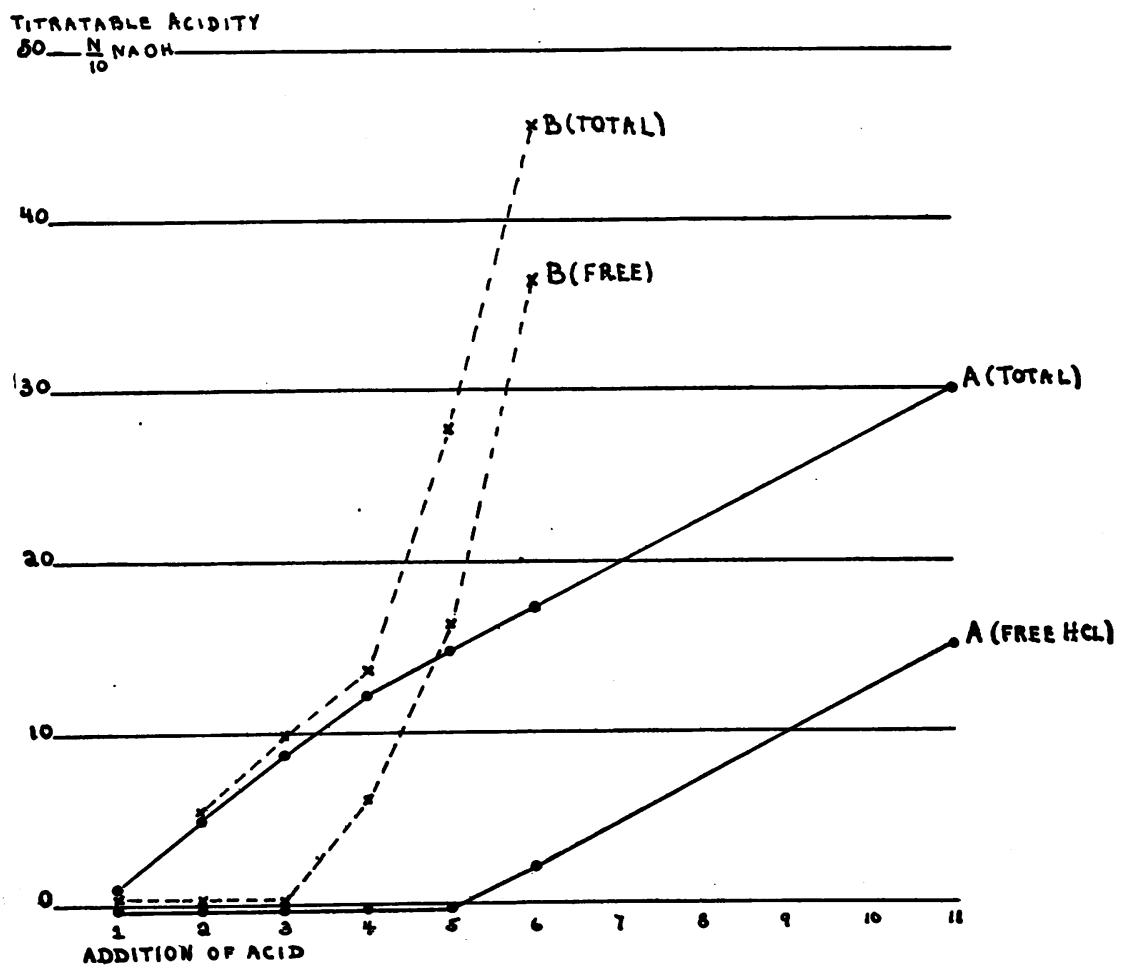

Chart 5. Artificial Test Meals-Acid Curves 
the rate of acid secretion alone, but on the rate of gastric emptying as well, and an obvious explanation is furnished for the clinical instances in which on one examination no free acid is found, whereas at another time free acid is present. At any rate great caution should be used in interpreting the so-called "secretory curves" after fractional meals unless the rate of emptying of the stomach is known.

\section{SUMMARY}

Study of rate of gastric secretion after the alcohol test meal shows that in almost every case maximum volume of secretion and maximum degree of acidity of gastric juice is reached promptly and not gradually. This finding is reconciled with the apparently contradictory "curves of acidity" obtained with fractional test meals by pointing out certain artefacts which may modify the latter.

\section{BIBLIOGRAPHY}

1. Crohn, B. B., and Reiss, J., Am. J. Med. Sci., 1917, cliv, 857. Studies in Fractional Estimations of Stomach Contents.

2. Bloomfield, A. L., and Keefer, C. S., J. Am. Med. Assoc., 1927, lxxxviii, 707. Clinical Studies of Gastric Function.

3. Gorham, F. D., J. Am. Med. Assoc., 1923, lxxxi, 1738. The Factor of Dilution in Gastric Analysis. 